\title{
Relationship between listening, speech and language, cognition and pragmatic skill in children with cochlear implant
}

\author{
Himanshu Kumar Sanju ${ }^{1 *}$, Divya Rawat ${ }^{2}$, Arun Kumar Yadav ${ }^{3}$ \\ ${ }^{1,3}$ Assistant Professor, ${ }^{2}$ Student, Dept. of ENT and Audiology, ${ }^{1}$ Sri Jagdamba Andh Vidyalaya Samiti, Rajasthan, ${ }^{2,3}$ Amity \\ University, Haryana, India
}

*Corresponding Author: Himanshu Kumar Sanju

Email: ayarunkumar1@gmail.com

\begin{abstract}
Purpose: Previous literature has reported early identification and treatment of hearing loss has a positive effect on overall speech and language development, social skill, cognitive skill as well as pragmatic skill. Present study aimed to measure correlation between listening, speech and language, cognition and pragmatic skill in children with cochlear implant.

Materials and Methods:A total of 20 children with cochlear implant in the age range of 1.5 to 5 years participated in the present study. Integrated Scale of Development from listen, learn and talk was used to find out listening, speech and language, cognition and pragmatic age in children with cochlear implant.

Results: The outcome of present study revealed strong correlation between listening, speech and language, cognition and pragmatic age in children with cochlear implant.

Conclusion: The finding of the present study revealed enhancement in one domain of communication skill leads to improved performance in other domains.
\end{abstract}

Keywords: Cognition, Cochlear implant, Listening, Speech and language, Pragmatic.

\section{Introduction}

Recent Investigation revealed that early identification and management of hearing loss has positive effect on speech, language and communication..$^{1-4}$ Young children with hearing impairment fitted with traditional hearing devices (hearing aid) and cochlear implant. Previous research has shown that children using cochlear implant perform better in speech and language skill compared to children using traditional amplification devices. ${ }^{3-4}$ A study done by Yoshinaga, Sedey, Wiggin and Mason in 2018 reported earlier cochlear implant activation had a positive and direct outcome on speech and language skill. ${ }^{5}$ Dettman et al., in 2016 concluded that cochlear implantation in children younger than 12 months of age has positive effect on language skill and articulation accuracy. ${ }^{6}$ Recently, Cejas, Mitchell, Hoffman and Quittner in 2018 revealed similar intelligence quotient (IQ) between typically developing children and children with cochlear implant. ${ }^{7}$ Cochlear implant provides opportunity to children with hearing impairment to develop speech-language whereas intensive intervention must be given to improve pragmatic skill among these children. ${ }^{8}$ However, in an another study authors reported no difference in pragmatic skill between children using cochlear implant and hearing aid. ${ }^{9}$ Ibertsson, Hansson, Torkko, Svensson and Sahlen in 2007 reported children with CI performed equal responsible conversational partners as the normal hearing teenagers. ${ }^{10}$

From the previous literature it can be observed that there is a lack of investigation regarding correlation between listening, speech and language, cognition and pragmatic age in children with cochlear implant. ${ }^{1-4}$ There is a need to study correlation between listening, speech and language, cognition and pragmatic age in children with cochlear implant.

The aim of the study was to investigate correlation between listening, speech and language, cognition and pragmatic age in children with cochlear implant. The objective of the study was to find listening, speech and language, cognition and pragmatic age of children using cochlear implant. The other objective was to check correlation between listening, speech and 
language, cognition and pragmatic age of the children using cochlear implant.

\section{Materials and Methods}

A total of 20 children in the age range of 1.5 to 5 years who were using the Nucleus Sound Processor cochlear recruited from a private clinic of audiology based in New Delhi, India. All children belong from the families with good socioeconomic status. Parents of all children were well educated with a minimum graduate degree. Informed written and oral consent were taken from the parents of all children participated in the study. In the present study Integrated Scale of Development from listen, learn and talk was used to calculate listening, speech and language, cognition and pragmatic age in children with cochlear implant. Data was collected by two qualified audiologist with master degree in audiology. Mean and standard deviation were calculated using SPSS 20. Spearman correlation analysis was done to check for correlation between different variables i.e. listening, speech and language, cognition and pragmatic age.

\section{Results and Discussion}

The finding of the present study revealed very strong significant positive correlation between listening and receptive language age $(\mathrm{r}=0.95, \mathrm{p}<0.05)$, listening and expressive language age $(r=0.98, p<0.05)$, listening and speech skill age $(\mathrm{r}=0.93, \mathrm{p}<0.05)$, listening and cognition age $(\mathrm{r}=0.89, \mathrm{p}<0.05)$, listening and pragmatic age $(r=0.95, p<0.05)$. Similarly, current study also revealed very strong significant positive correlation between receptive and expressive language age $(\mathrm{r}=0.97, \mathrm{p}<0.05)$, receptive and speech skill age $(\mathrm{r}=0.93, \mathrm{p}<0.05)$, receptive and cognition age $(\mathrm{r}=0.93$, $\mathrm{p}<0.05)$, receptive and pragmatic age $(\mathrm{r}=0.94, \mathrm{p}<0.05)$. The very strong significant positive correlation also observed betweenexpressive and speech skill age $(\mathrm{r}=0.95, \quad \mathrm{p}<0.05)$, expressive and cognition age $(\mathrm{r}=0.90, \mathrm{p}<0.05)$, expressive and pragmatic age $(\mathrm{r}=0.94, \mathrm{p}<0.05)$. The interesting finding of the present study was very strong significant positive correlation between cognition and pragmatic age $(\mathrm{r}=0.94, \mathrm{p}<0.05)$. The outcome of the present study revealed enhancement in one domain of communication skill leads to improved performance in other domains. The finding of the current study also showed that improvement in receptive and expressive language skills also improve cognition and pragmatic skill in the children using cochlear implant.

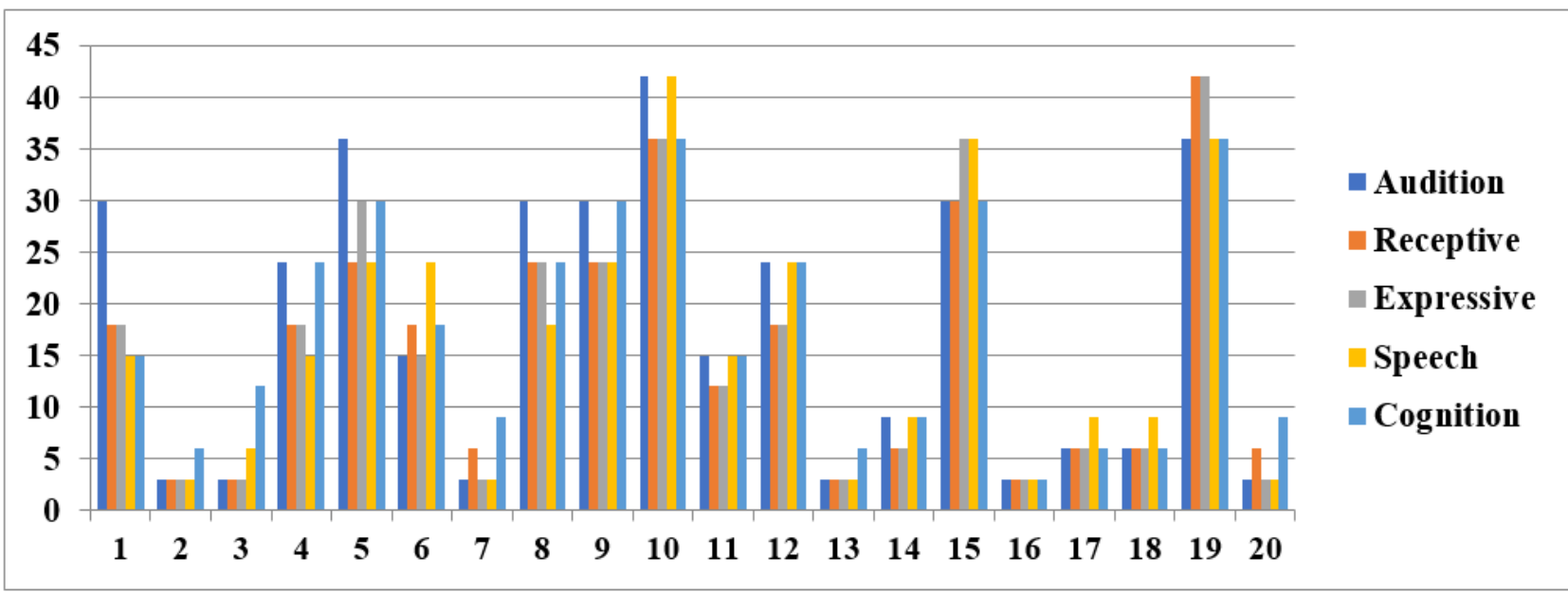

Fig. 1: Bar graph represents the scores ( $\mathrm{Y}$ axis) of individual subject ( $\mathrm{X}$ axis) 


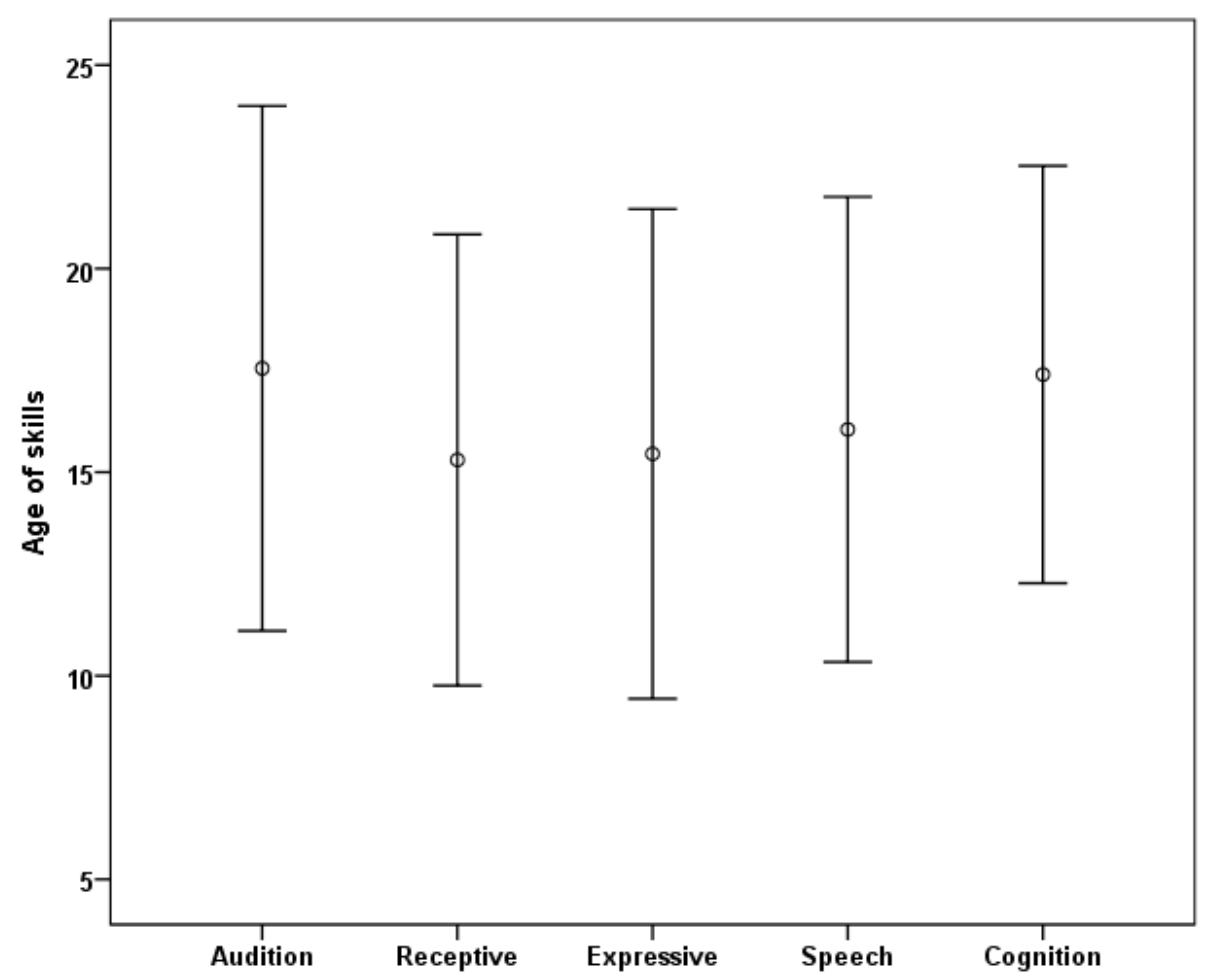

Fig. 2: Error bar graph showing mean and standard deviation of audition, receptive, expressive, speech and cognition age.

\section{Summary and Conclusion}

The outcome of the present study showed very strong positive correlation between listening, speech and language, cognition and pragmatic age in children with cochlear implant. The finding of the present study revealed enhancement in one domain of communication skill leads to improved performance in other domains.

\section{Source of funding}

None.

\section{Conflict of interest}

Nil

\section{References}

1. Robbins AM, Koch DB, Osberger MJ, ZimmermanPhillips S, Kishon-Rabin L. Effect of age at cochlear implantation on auditory skill development in infants and toddlers. Arch Otolaryngol-Head Neck Surg 2004;130(5):570-4.

2. Niparko JK, Tobey EA, Thal DJ, Eisenberg LS, Wang NY, Quittner AL, Fink NE, CDaCI Investigative Team. Spoken language development in children following cochlear implantation. JAMA 2010;303(15):1498-506.

3. Geers AE, Moog JS, Biedenstein J, Brenner C, Hayes H. Spoken language scores of children using cochlear implants compared to hearing age-mates at school entry. J Deaf Stud Deaf Educ 2009;14(3):371-85.

4. Warner-Czyz AD, Geers A, Wang NY, Mitchell C, Wiseman KB, Decker J, Eisenberg L. Salient predictors of normal speech development in long-term pediatric cochlear implant users. J Hearing Sci 2018;8(2):459-63.

5. Yoshinaga-Itano C, Sedey AL, Wiggin M, Mason CA. Language Outcomes Improved Through Early Hearing Detection and Earlier Cochlear Implantation. Otol Neurotol 2018;39(10):1256-63.

6. Dettman SJ, Dowell RC, Choo D, Arnott W, Abrahams Y, Davis A, Dornan D, Leigh J, Constantinescu G, Cowan R, Briggs RJ. Long-term communication outcomes for children receiving cochlear implants younger than 12 months: A multicenter study. Otol Neurotol 2016;37(2):8295.

7. Cejas I, Mitchell CM, Hoffman M, Quittner AL, CDaCI. Investigative Team. Comparisons of IQ in Children With and Without Cochlear Implants: Longitudinal Findings and Associations with Language. Ear and Hearing. 2018;39(6):1187-98.

8. Rinaldi P, Varuzza C, Giuliani A, Burdo S. Cochlear implant in the second year of life: Lexical and grammatical outcomes. J Speech, Lang, Hear Res 2012;55(2):382-94. 
9. Most T, Shina-August E, Meilijson S. Pragmatic abilities of children with hearing loss using cochlear implants or hearing aids compared to hearing children. J Deaf Stud Deaf Educ 2010;15(4):422-37.

10. Ibertsson T, Hansson K, Mäki-Torkko E, WillstedtSvensson U, Sahlen B. Deaf teenagers with cochlear implants in conversation with hearing peers. Int J Lang Commun Disord 2009;44(3):319-37.

How to cite this article: Sanju HK, Rawat D,
Yadav AK. Relationship between listening, speech
and language, cognition and pragmatic skill in
children with cochlear implant. Indian J Anat Surg
Head Neck Brain 2019;5(3):72-5.

